\title{
Clustering of metabolic syndrome and its risk factors among adult Nigerians in a national health insurance scheme primary care clinic of a tertiary hospital in south-eastern Nigeria
}

\author{
Gabriel Uche Pascal Iloh ${ }^{1,}$, , Orji Udo Nnorom ${ }^{1}$, Patrick Uchenna Njoku', \\ Godwin Oguejiofor Chukwuebuka Okafor ${ }^{2}$, Augustine Obiora Ikwudinma ${ }^{3}$ \\ ${ }^{1}$ Department of Family Medicine, Federal Medical Centre, Umuahia, Nigeria \\ ${ }^{2}$ Department of Community Medicine, Federal Medical Centre, Umuahia, Nigeria \\ ${ }^{3}$ Department of Family Medicine, Federal Teaching Hospital Abakiliki, Nigeria
}

\section{Email address:}

ilohgup2009@yahoo.com (G. U. P. Iloh)

To cite this article:

Gabriel Uche Pascal Iloh, Orji Udo Nnorom, Patrick Uchenna Njoku, Godwin Oguejiofor Chukwuebuka Okafor, Augustine Obiora Ikwudinma. Clustering of Metabolic Syndrome and its Risk Factors among Adult Nigerians in a National Health Insurance Scheme Primary Care Clinic of a Tertiary Hospital in South-Eastern Nigeria. American Journal of Health Research. Vol. 2, No. 2, 2014, pp. 33-42. doi: 10.11648/j.ajhr.20140202.11

\begin{abstract}
Background: The increasing incidence of MetS in Nigeria is a national health problem. As the case detection of MetS increases in different Nigerian populations evaluating for its clusters among NHIS patients in primary care setting is an important health service challenge that is often overlooked. Aim: This study was designed to determine the prevalence of MetS and its risk factors among adult Nigerians in a NHIS primary care clinic of a tertiary hospital in South-eastern Nigeria.Materials and Methods: This was a primary care clinic-based cross sectional study carried out on 210 adult NHIS patients using International Diabetes Federation(IDF) criteria: An Individual was considered to have MetS in the presence of waist circumference $(\mathrm{WC}) \geq 94 \mathrm{~cm}$ for men and $\geq 80 \mathrm{~cm}$ for women plus any two or more of the following: systolic and/or diastolic blood pressure $\geq 130 / 85 \mathrm{mmHg}$ and/or hypertension on treatment; fasting blood glucose $\geq 100 \mathrm{mg} / \mathrm{dL}$ and/or diabetes mellitus on treatment; triglyceride level $\geq 150 \mathrm{mg} / \mathrm{dL}$ and/or hypertriglyceridaemia on treatment and high density lipoprotein(HDL-C) cholesterol $<40 \mathrm{mg} / \mathrm{dL}$ for men or $<50 \mathrm{mg} / \mathrm{dL}$ for women and/or HDL-C dyslipidaemia on treatment. Data was collected using pretested, structured and researcher administered questionnaire. Results: The prevalence of MetS was $38.6 \%$. MetS was significantly associated with old age $\geq 40$ years $(\mathrm{p}=.002)$, female sex $(\mathrm{p}=.044)$, family history of hypertension $(\mathrm{p}=.036)$ and physical inactivity $(\mathrm{p}=.001)$. The most significant predictor of MetS was physical inactivity.[OR=3.09, $\mathrm{CI}=(1.81-10.06), \mathrm{p}=.001]$. The patients with MetS were three times more likely to be physically inactive compared to their non-MetS counterparts. Conclusion: This study has shown that MetS exist among the study population and was significantly associated with old age $\geq 40$ years, female sex, family history of hypertension and physical inactivity. The most significant predictor variable was physical inactivity. NHIS patients in the primary care clinic should be the focus of primary and secondary preventive interventions for MetS.
\end{abstract}

Keywords: Adult Nigerians, Mets, NHIS, Prevalence, Primary Care Clinic, Risk Factors

\section{Introduction}

Metabolic syndrome (MetS) is a global medical problem $[1,2]$ presently escalating in developing countries[3,4]] as an important component of non-communicable disease burden. It is a multi-factorial disorder that represents a clustering of risk factors that lead to an increased incidence of cardio-metabolic disorders.[5-8] Specific set of criteria have been used by different Working Groups for clinical and epidemiological diagnoses of MetS.[9-13] The set of criteria include the revised third report of National Cholesterol Education Panel(NCEP) in adult (ATP III) criteria(NCEP-ATP III),[9] World Health Organization(WHO) criteria,[10] International Diabetes 
Federation(IDF) criteria,[11] American College of Endocrinology criteria(ACE)[12] and The European Group for the study of Insulin Resistance(EGIR)criteria.[13] The most widely used clinic-based MetS diagnostic criteria are those of IDF-criteria and NCEP-ATP III criteria.[3,14] The defining elements of MetS using IDF-criteria is the presence of waist circumference (WC) $\geq 94 \mathrm{~cm}$ for men and $\geq 80 \mathrm{~cm}$ for women plus any two or more of the following: systolic and/or diastolic blood pressure $\geq 130 / 85 \mathrm{mmHg}$ and/or hypertension on treatment; fasting blood glucose $\geq$ $100 \mathrm{mg} / \mathrm{dL}$ and/or diabetes mellitus on treatment; triglyceride level $\geq 150 \mathrm{mg} / \mathrm{dL}$ and/or hypertriglyceridaemia on treatment and high density lipoprotein(HDL-C) cholesterol $<40 \mathrm{mg} / \mathrm{dL}$ for men or $<50 \mathrm{mg} / \mathrm{dL}$ for women and/or HDL-C dyslipidaemia on treatment.[11]

The prevalence of MetS varies by definitions and diagnostic criteria across different parts of the world: In United States of America(USA) the prevalence varies from $16 \%$ of black men to $37 \%$ of Hispanic women[15], prevalence of $39.3 \%$ was reported in Saudi Arabia[16], $29.7 \%$ was reported in India[17] and $35.9 \%$ in Ghana,[18] $43.3 \%$ was reported in Ethiopia,[19] $15.9 \%$ was reported in Enugu, South eastern Nigeria[20] and $14.9 \%$ was reported in Abuja, Nigerian capital city.[21]

The magnitude of MetS has been reported in specific high risk patients population such as those who were obese: prevalence of $46.3 \%$ was reported in Quatar, [22] $40.2 \%$ was reported in Malaysia[23], and $53.0 \%$ was reported in Italy.[24] Among patients with type 2 diabetes mellitus, the prevalence of metabolic syndrome of $77.2 \%$ was reported in diabetics in India.[25], 25.2\% was reported in diabetics in Western Nigeria[26] and 63.6\%\% was reported in Jos, Northern Nigeria.[27] In hypertensive patients prevalence of $15.9 \%$ was reported in Enugu, South eastern Nigeria [20] and prevalence of $42.9 \%$ was reported in Osogbo, Western Nigeria.[14]

The variability of MetS syndrome within and across the world population is a factor of genetic(family history),[28] metabolic[29] and socio-environmental factors.[7,30,31] The predominant underlying risk factors of MetS appear to be insulin resistance[5] and abdominal obesity. [32] The associated risk factors include physical inactivity $[6,15]$ and other enhancing risk factors. $[6,8]$

There have been reports of on the emergence of MetS in different populations in Nigeria.[7,14,20,21,26,27] However nothing is known about the magnitude of MetS in primary care clinic of NHIS in Nigeria. These NHIS patients were sampled because they are patients' population likely to be affected by adoption of western lifestyle characterized by sedentary lifestyle, consumption of fast foods amidst other non-constitutional factors that cluster in dysmetabolic syndrome. Of great concern in the study area is that MetS is serendipitously found in NHIS patients in the primary care clinic of the hospital and MetS also occur concurrently in adult patients with component defining criteria for MetS at initial diagnosis. Even in mild degrees, MetS has serious medical consequences and poses additional socio-psychological challenges leading to poor quality of life and may have untoward direct and indirect consequences on work force aliveness and productivity. In view of the epidemiological transition towards cardiometabolic disorders in Nigeria[33], establishing a baseline for the distribution and determinants of MetS in these patients and evaluating them during subsequent patients visits appropriately can provide primary care physicians with excellent means of educating their patients on lifestyle modifications. It is on this premise that the authors were motivated to determine the prevalence of MetS and its risk factors among adult Nigerians in a National Health Insurance Scheme(NHIS) primary care clinic of a tertiary hospital in South-eastern Nigeria.

\section{Materials and Methods}

\subsection{Ethical Consideration}

Ethical certificate was obtained from the Health Research and Ethics Committee of the hospital. Informed consent was also obtained from patients included in the study.

\subsection{Study Design}

This was a primary care clinic-based cross sectional study carried out on 210 adult Nigerians attending the NHIS primary care clinic between February 2012 and May 2012 at the department of Family Medicine of Federal Medical Centre, Umuahia, a tertiary hospital in Umuahia, Abia state, South-Eastern, Nigeria.

\subsection{Study Setting}

Umuahia is the capital of Abia state, South-East Nigeria. The State is endowed with abundant mineral and agricultural resources with supply of professional, skilled, semi-skilled and unskilled manpower. Economic and social activities are low compared to industrial and commercial cities such as Onitsha, Port Harcourt and Lagos in Nigeria. Until recently, the capital city and its environ have witnessed an upsurge in the number of banks, hotels, schools, markets, industries, junk food restaurants in addition to the changing dietary and social lifestyles.

Federal Medical Centre, Umuahia is located in the metropolitan city of Umuahia. It is a tertiary hospital established with the tripartite mandate of service delivery, training and research and serves as a referral Centre for primary and secondary public health institutions as well as missionary and private hospitals in Abia state and neighbouring states of Imo, Ebonyi, Rivers and Akwa Ibom states of Nigeria.

The department of Family Medicine serves as a primary care clinic for NHIS patients within the tertiary hospital setting of the Federal Medical Centre. All adult patients excluding those who need emergency services, paediatric patients and antenatal women are first seen at the department of Family Medicine where diagnoses are made. 
Patients who need primary care are managed and followed up in the clinic while those who need other specialists care are referred to the respective core specialist clinics for further management. The clinic is run by Consultant Family Physicians and postgraduate resident doctors in Family Medicine.

\subsection{Study Population}

The study population was made up of 210 adult NHIS patients who had $\mathrm{WC} \geq 94 \mathrm{~cm}$ for men and $\geq 80 \mathrm{~cm}$ for women using IDF criteria and who met the inclusion criteria.

\subsection{Inclusion and Exclusion Criteria}

The inclusion criteria were NHIS patients with $\mathrm{WC} \geq 94$ $\mathrm{cm}$ for men and $\geq 80 \mathrm{~cm}$ for women aged $\geq 18$ years who gave informed consent for the study. The exclusion criteria were critically ill patients, pregnant women, women in pueperium, patients with demonstrable ascites and intraabdominal masses determined by history and physical examination.

\subsection{Sample Size Determination}

Sample size estimation was determined using the formula[34] for calculating minimum sample size $\mathrm{N}=\mathrm{Z}^{2} \mathrm{pq} / \mathrm{d}^{2}$ where $\mathrm{N}=$ Minimum sample size, $\mathrm{Z}=$ Standard normal deviation usually set at 1.96 which corresponds to 95\% confidence interval, $\mathrm{P}=$ Proportion of the population estimated to have a particular characteristic. Proportion was taken from previous study in Abuja, Nigeria [21] $=14.9 \%$ (0.15). $\mathrm{q}=1.0-\mathrm{p}=1.0-0.15=0.85, \mathrm{~d}=$ degree of accuracy set at 0.05 . Hence $\mathrm{N}=(1.96)^{2} \times 0.15 \times 0.85 /(0.05)^{2}$. Therefore, $\mathrm{N}=196$. The calculated minimum sample size was 196. However, to improve the precision of the study, the estimated sample size $=\mathrm{Ns}$ was determined considering an anticipated response rate of $90 \%(0.9)$. The estimated sample size (Ns) was determined by dividing the original calculated sample size $(\mathrm{N})$ by the anticipated response rate as follows, Ns= N/0.9, [34] where $\mathrm{N}=$ Minimum calculated sample size, Ns=Selected sample size, anticipated response rate $=0.9$. Thus, the estimated sample size $=196 / 0.9=217$. However, selected sample size of 210 patients was used based on the duration of the study.

\subsection{Sampling Technique}

The sample selection was done consecutively using every NHIS adult patient who registered to see the clinicians on each consulting day during the study period and who met the inclusion criteria. This sampling technique was judge mentally chosen by the authors based on the fact that the researchers believed that those selected were likely to be representative of the study population.

\subsection{Diagnostic Procedure for Mets}

Metabolic syndrome components were evaluated by anthropometric determination of waist circumference, clinical evaluation of blood pressure and laboratory assessment of fasting plasma glucose and lipid profile.

The WC was measured using flexible non-stretchable tape.[35,36] The subject stood erect with arms at the side and feet together. The researcher faced the subject. The iliac crest and lower rib cage were first identified by palpation. The WC was taken as the midpoint between the lower border of lower rib cage and iliac crest in a horizontal plane parallel to the floor.

The blood pressure was measured using auscultatory method with standard mercury in glass Accuson sphygmomanometer.[35-37] Prior to the measurement, the patient was seated and rested for 5 minutesin sitting position on a chair that supported the back comfortably. The left arm muscles were relaxed and the forearm was supported with the cubital fossa at the heart level. A cuff of suitable size was applied evenly to the exposed arm. The cuff was rapidly inflated until the manometer reading was about $30 \mathrm{mmHg}$ above the level at which the pulse disappeared and then slowly deflected. During this time, the Korotkoff sounds were monitored using a Litman stethoscope placed over the brachial artery. The systolic blood pressure was noted at the pressure at which the first heart sounds were heard(Korotkoff phase I). The diastolic blood pressure was taken as the pressure at the point when the heart sounds disappeared(Korotkoff phase v). The blood pressure was also measured in the right arm as described for the left arm in order to rule out significant inter-arm blood pressure difference and the arm that gave the higher reading was subsequently used.

The blood glucose was determined after an overnight fast between 8.00 hours to 10.00 hours using venous plasma by glucose oxidase method.[35-37]

The fasting lipid profile: triglycerides and high density lipoprotein cholesterol were determined after an overnight fast between 8.00 hours to 10.00 hours by enzymatic method.[35-37]

\subsection{Diagnostic Criteria for Mets Using IDF Criteria}

The Metabolic syndrome was defined using IDF-criteria, [11] an Individual was considered to have MetS in the presence of waist circumference $(\mathrm{WC}) \geq 94 \mathrm{~cm}$ for men and $\geq 80 \mathrm{~cm}$ for women plus any two or more of the following: systolic and/or diastolic blood pressure $\geq 130 / 85 \mathrm{mmHg}$ and/or hypertension on treatment; fasting blood glucose $\geq$ $100 \mathrm{mg} / \mathrm{dL}$ and/or diabetes mellitus on treatment; triglyceride level $\geq 150 \mathrm{mg} / \mathrm{dL}$ and/or hypertriglyceridaemia on treatment and high density lipoprotein(HDL-C) cholesterol $<40 \mathrm{mg} / \mathrm{dL}$ for men or $<50 \mathrm{mg} / \mathrm{dL}$ for women and/or HDL-C dyslipidaemia on treatment.

\section{Methods}

Data collection instrument was adapted from the generic WHO-STEPS instrument approach to surveillance of chronic non-communicable diseases risk factors [38] and 
was modified to suit Nigeria environment through robust review of relevant literature $[4,7,20,22,23,30,31,36,39,40]$ The socio-demographic variables of age, sex, marital status, education and personal histories and diagnoses of principal components of metabolic syndrome were obtained. The behavioural factors assessed were physical activity profile, alcohol and tobacco use, dietary fruits and vegetables consumption during meal times and the type of oils used in meal preparations.

The family history of hypertension, diabetes mellitus, abdominal obesity and stroke was coded as yes or no for the presence or absence of hypertension, diabetes mellitus, abdominal obesity and/or stroke in any of the first, second or third degree generation family members respectively.

The behavioural risk factor of physical activity was assessed by inquiring how many times the respondents engaged in physical activities in the previous 7 days. Those who engaged in activities that cause a moderate or large increase in breathing or heart rate for $\geq 30$ minutes for $\geq 3$ days/week were considered physically active while the level of activity below this was considered physical inactivity. Subject's occupational, leisure-related and activities of daily living were taken into account in assessing for the physical activity. Physical activity responses were graded into: never (0 times/week), rarely ( $<30$ minutes in $<3$ days/week $)$ and often times $(\geq 30$ minutes in $\geq 3$ days/week). Physical activity was categorized as active or inactivity. Those who had 0 time/week(never) or <30 minutes in <3 days/week(rarely) were considered physically inactive while those who had $\geq 30$ minutes in $\geq 3$ days/week (oftentimes) were considered physically active. Alcohol consumption was assessed in the previous 12 months preceding the study and coded yes or no for someone who used less than a unit or a unit of any type of alcohol daily or occasionally in 12 months preceding the study or someone who had never used alcohol in the previous 12 months preceding the study respectively. A unit of alcohol is equivalent to $10 \mathrm{~g}$ of alcohol. Similarly, tobacco use was evaluated with respect to the use of smoked and smokeless tobacco in the lifetime and coded yes or no for someone who had used smoked or smokeless tobacco in any form either daily or occasionally in their lifetime or someone who had never used tobacco in their lifetime respectively. The dietary fruits and vegetables consumption were evaluated by asking how many days in the previous 7 days did the respondents eat fruits and vegetables. The dietary responses were graded into: never ( 0 serving/week), rarely ( $<3$ servings/week) and oftentimes ( $\geq 3$ servings/week). Those who had $\geq 3$ servings/week had adequate dietary fruits intake while those who had 0 serving/week and <3 servings/week had inadequate dietary fruits and vegetables consumption respectively. The question on dietary use of oils was got by inquiring in the previous 7 days the type of oil used in household meal preparations. The dietary oils were classified into saturated and unsaturated oils based on the type of oils available in Nigeria.
The information on personal behavioural measurements was based on previous 7 days physical activity and dietary recall method. This method was expected to give required information on physical activity and dietary assessment based on the feasibility and the Nigerian practice population setting. The researchers explained briefly the concept of the study and made vigorous effort to maximize positive response in order to minimize the potential for information bias especially response acquiescence, social desirability response, floor and ceiling effects.

The pre-testing of the questionnaire was done internally at the primary care clinic using five non-NHIS patients who had MetS. The pre-testing of the questionnaire lasted for two days. The respondents for the pre-testing of the questionnaire were selected haphazardly from the clinic. The pretesting was done to find out how the questionnaire would interact with the respondents and ensured that there were no ambiguities. However, no change was necessary after the pre-test as the questions were interpreted with the same meaning as intended. The questionnaire instrument was interviewer-administered. Language used was English Language. However, local languages were used to explain verbally to the patients who could not understand the medical language in the questionnaire. The questionnaire was administered once to each eligible respondent.

\subsection{Operational Definitions}

The researchers defined young adult patients as those aged less than 40 years and old adults as those $\geq 40$ years. Biosocial risk factors of MetS refer to antecedent condition(s) whose presence is(are) positively associated with an increased probability that MetS will develop later. Family history of component defining criteria for MetS such hypertension, type 2 diabetes mellitus and/or abdominal obesity refers to previous information on the occurrence of hypertension, type 2 diabetes mellitus and/or abdominal obesity in any of the first, second or third degree generation family members who were dead or alive made by a health professional. Primary care refers to the care provided by physicians specifically trained for comprehensive first contact and continuing care for undifferentiated patients including early detection, management of the patient, health promotion and maintenance.[36]

\subsection{Statistics}

The results generated were analyzed using software Statistical Package for Social Sciences (SPSS) version 13.0, Microsoft Corporation, Inc. Chicago, IL, USA. Categorical variables were described by frequencies and percentages. Bivariate analysis involving Chi-square test was used to test for the significance of associations between categorical variables. To determine the odd ratio, the authors controlled for the patients with MetS using those without MetS within the study population. Furthermore, to identify predictor variables independently related with MetS, logistic 
regression analysis was performed at $95 \%$ confidence limit. A p-value $\mathrm{p}<.05$ and/or confidence limits which didn't embrace unity(1) were considered statistically significant.

\section{Results}

Of the 210 patients who had abdominal obesity, $38.6 \%(81)$ had MetS. [Table 1] The age of these patients ranged from 18 years to 60 years with a mean age of $43 \pm$ 5.1 years. There were $69(32.9 \%)$ males and $141(67.1 \%)$ females with male to female ratio of 1 : 2 . Other demographic profiles of the study population are shown in table 2 .

Bivariate analysis of the relationship between MetS, socio-demographic variables, family history and lifestyle factors showed that variables such as old age $\geq 40$ years $\left(\mathrm{X}^{2}=7.10, \quad \mathrm{p}\right.$-value=.002); female sex $\left(\mathrm{X}^{2}=5.26, \quad \mathrm{p}\right.$ value $=.044)$, family history of hypertension $\left(X^{2}=8.80, p-\right.$ value=.036) and physical inactivity $\left(\mathrm{X}^{2}=12.70, \mathrm{p}=0.001\right)$ were statistically significant while other variables such as marital status $(\mathrm{p}=.210)$, educational attainment $(\mathrm{p}=.098)$, family history of diabetes $(\mathrm{p}=.116)$, family history of abdominal obesity $(\mathrm{p}=.204)$, family history of stroke $(\mathrm{p}=.088)$, alcohol consumption( $\mathrm{p}=.330)$, tobacco use $(\mathrm{p}=.399)$, dietary fruits consumption $(\mathrm{p}=.094)$, dietary vegetables consumption( $\mathrm{p}=.075)$ and dietary oils consumption $(\mathrm{p}=.091)$ were not statistically significant. [Table 2].

Table 1. Distribution of the patients'based on MetS status using IDF diagnostic criteria.

\begin{tabular}{lll}
\hline Parameter (Status) & Number & Percentage \\
\hline MetS present & 81 & 38.6 \\
MetS absent & 129 & 61.4 \\
Total & 210 & 100.0 \\
\hline
\end{tabular}

Table 2. Relationship between MetS, socio-demographic variables, family history and lifestyle factors among the study population.

\begin{tabular}{|c|c|c|c|c|c|}
\hline Variable & $\begin{array}{l}\text { Metabolic sy } \\
\text { Present } \\
\mathrm{N}=81 \\
\text { Number(\%) }\end{array}$ & $\begin{array}{l}\text { Absent } \\
\mathrm{N}=129 \\
\text { Number(\%) }\end{array}$ & $\mathbf{X}^{2}$ & & P-value \\
\hline \multicolumn{6}{|l|}{ Age(years) } \\
\hline$<40$ & $25(30.9)$ & $87(67.4)$ & & & \\
\hline$\geq 40$ & $56(69.1)$ & $42(32.6)$ & 7.10 & & $.002 *$ \\
\hline \multicolumn{6}{|l|}{ Sex } \\
\hline Male & $29(35.8)$ & $40(31.0)$ & & & \\
\hline Female & $52(64.2)$ & $89(69.0)$ & 5.26 & & $.044 *$ \\
\hline \multicolumn{6}{|l|}{ Marital status } \\
\hline Single & $13(16.0)$ & $29(22.5)$ & & & \\
\hline Married & $61(75.3)$ & $92(71.3)$ & & & \\
\hline Widowed & $5(6.2)$ & $4(3.1)$ & & & \\
\hline Separated/Divorced & $2(2.5)$ & $4(3.1)$ & 4.03 & & .210 \\
\hline \multicolumn{6}{|l|}{ Education } \\
\hline Secondary and less & $70(86.4)$ & $22(17.1)$ & & & \\
\hline Post-secondary and more & 11(13.6) & $107(82.9)$ & 6.16 & .098 & \\
\hline \multicolumn{6}{|c|}{ Family history of hypertension } \\
\hline Yes & $61(75.3)$ & $78(60.5)$ & & & \\
\hline No & $20(24.7)$ & $51(39.5)$ & 8.80 & & $.036^{*}$ \\
\hline \multicolumn{6}{|l|}{$\begin{array}{l}\text { Family history of type } 2 \\
\text { diabetes }\end{array}$} \\
\hline Yes & $26(32.1)$ & $17(13.2)$ & & & \\
\hline No & $55(67.9)$ & $112(86.8)$ & 4.70 & & .116 \\
\hline \multicolumn{6}{|l|}{$\begin{array}{l}\text { Family history of } \\
\text { abdominal obesity }\end{array}$} \\
\hline Yes & 11(13.6) & $10(7.8)$ & & & \\
\hline No & $70(86.4)$ & $119(92.2)$ & 4.23 & & .204 \\
\hline \multicolumn{6}{|l|}{ Family history of stroke } \\
\hline Yes & $8(9.9)$ & $13(10.1)$ & & & \\
\hline No & $73(90.1)$ & $116(89.9)$ & 5.18 & & .088 \\
\hline \multicolumn{6}{|l|}{ Physical activity } \\
\hline Active & $12(14.8)$ & $33(25.6)$ & & & \\
\hline Inactive & $69(85.2)$ & $96(74.4)$ & 12.70 & & $.001 *$ \\
\hline \multicolumn{6}{|l|}{ Alcohol consumption } \\
\hline Yes & $37(45.7)$ & $91(70.5)$ & & & \\
\hline No & $44(54.3)$ & $38(29.5)$ & 6.90 & & .330 \\
\hline \multicolumn{6}{|l|}{ Tobacco use } \\
\hline Yes & $10(12.3)$ & $18(14.0)$ & & & \\
\hline No & $71(87.7)$ & $111(86.0)$ & 5.70 & & .309 \\
\hline \multicolumn{6}{|l|}{ Dietary fruits consumption } \\
\hline Adequate & $15(18.5)$ & $39(30.2)$ & & & \\
\hline Inadequate & $66(81.5)$ & $90(69.8)$ & 8.01 & & .094 \\
\hline
\end{tabular}




\begin{tabular}{|c|c|c|c|c|}
\hline Variable & $\begin{array}{l}\text { Metabolic sy } \\
\text { Present } \\
\mathrm{N}=81 \\
\text { Number(\%) }\end{array}$ & $\begin{array}{l}\text { Absent } \\
\mathrm{N}=129 \\
\text { Number(\%) }\end{array}$ & $\mathbf{X}^{2}$ & P-value \\
\hline \multicolumn{5}{|c|}{ Dietary vegetables consumption } \\
\hline Adequate & $27(33.3)$ & $75(58.1)$ & & \\
\hline $\begin{array}{l}\text { Inadequate } \\
\text { Dietary oil cc }\end{array}$ & $54(66.7)$ & $54(41.9)$ & 7.55 & .075 \\
\hline Saturated & $13(16.0)$ & $19(14.7)$ & & \\
\hline Unsaturated & $68(84.0)$ & $110(85.3)$ & 5.65 & .091 \\
\hline
\end{tabular}

$*=$ Significant

On logistic regression of the statistically significant variables, old age $\geq 40$ years and physical inactivity remained statistically significant with physical inactivity being the most statistically significant predictor variable of MetS. A significantly higher proportion of patients with MetS were physically inactive compared to those without $\operatorname{MetS}(\mathrm{OR}=3.09, \mathrm{CI}=1.81-10.06$, p-value=.001). The patients who had MetS were three times more likely to be physically inactive compared to their non-MetS counterparts.[Table 3]

Table 3. Predictors of MetS among the cases.

\begin{tabular}{|c|c|c|c|c|}
\hline \multirow{2}{*}{ Variables } & \multirow{2}{*}{$\begin{array}{c}\text { Odd } \\
\text { ratio } \\
(\mathrm{OR})\end{array}$} & \multicolumn{2}{|c|}{ 95\% Confidence interval } & \multirow{2}{*}{ P-value } \\
\hline & & Lower & upper & \\
\hline \multicolumn{5}{|l|}{ Age(years) } \\
\hline$<40$ & 1.0 & & & \\
\hline$\geq 40$ & 2.05 & 0.86 & 11.01 & $.015^{*}$ \\
\hline \multicolumn{5}{|l|}{ Sex } \\
\hline Male & 1.0 & & & \\
\hline Female & 1.72 & 0.50 & 10.17 & .064 \\
\hline \multicolumn{5}{|c|}{ Family history of hypertension } \\
\hline No & 1.0 & & & \\
\hline Yes & 1.93 & 0.78 & 12.60 & .070 \\
\hline \multicolumn{5}{|l|}{$\begin{array}{l}\text { Physical } \\
\text { activity }\end{array}$} \\
\hline Active & 1.0 & & & \\
\hline Inactive & 3.09 & 1.81 & 10.06 & $.001 *$ \\
\hline
\end{tabular}

$*=\mathrm{S}$

\section{Discussion}

The prevalence of MetS of $38.6 \%$ in this study is higher than that reported in Enugu, South-east Nigeria(15.9\%)[20], Abuja, North-central Nigeria(14.9\%)[21], Ghana(35.9\%)[18] and other parts of the world like India(29.7\%).[17] and Turkey(34.6\%)[41] However, the prevalence of MetS of in this study is lower than that reported in Ethiopia(43.3\%)[19] and Saudi Arabia(39.3\%)[16]. The finding of this study has demonstrated that MetS is no longer the exclusive disease of affluent countries and occurs in proportion among the study population as an important component of noncommunicable disease burden in Nigeria.[14] The magnitude of this burden of MetS among the study population is clinically relevant and informative especially in an environment where hospital attendance are largely driven by the need for curative services rather than the imperative for preventive care. The reported prevalence of MetS in this study could be a reflection of the changing lifestyle of the study population who were public servants in an urban geographic construct which is favourable to the onset and perpetuating of MetS. Since Nigeria has fewer resources to manage MetS and its complications, the most effective primary care intervention is early diagnosis and treatment. The interventions should include effective partnership between the patients and committed team of health professionals depending on the clustered elements of MetS in the individual. Educating these patients on the relevance of MetS, its risk factors and its interpretations should be integrated as part of patient health education and counselling during clinical encounter in primary care settings. It is therefore relevant to identify primary and secondary preventive strategies that have benefit-to risk and benefit-to cost ratio of any therapeutic interventions for MetS. These preventive interventions should be inexpensive, widely available, feasible and culturally friendly.

The prevalence of MetS was significantly associated with old age $\geq 40$ years. The old adults aged $\geq 40$ years were significantly affected compared to the young adults. This is in consonance with the reports that age is epidemiologically established non-modifiable and constitutional risk factor for the defining elements of MetS[16,17,22] According to these reports, the prevalence of MetS as defined by IDF criteria increases with age suggesting that age is related to each of the component of MetS. [16,17,22] Despite the age-related metabolic changes that predispose to MetS, knowledge of these subtleties is vital in primary care settings and maintaining high index of suspicion is advocated. This appears to be the only way old adult Nigerian public servants will benefit from reduction in specific and all cause mortality from MetS-related unnecessary deaths. The high prevalence of MetS among this age group paints a gloomy picture in the Nigerian labour force as this age group constitutes the most economically productive years who are expected to take active manpower duties and responsibilities in the country. Screening old adults' $\geq 40$ years for MetS in NHIS clinics should be integrated as part of comprehensive health care protocol for MetS in primary care.

The prevalence of MetS was significantly higher among females compared to their male counterparts $(p=)$. This finding is similar to reports from Nigeria,[7,21] and other 
parts of the world such as Ghana[18] India[17] and turkey[41]. The higher prevalence of MetS among the females in this study could be a reflection of IDF cut off criteria which is lower for females than males in Nigeria.[4,14] Apart from the diagnostic criteria, the genetic and lifestyle-related differences between the sexes may be contributory.

The family history of hypertension was significantly associated with MetS. This could be a reflection that hypertension which is a component of MetS as the most common non-communicable disease in Nigeria[35] and tends to cluster in persons with family history of hypertension.[39,42-44] The emergence of hypertensionrelated MetS is therefore a reflection of not only genetic predisposition but also susceptibility and interactions between genetic and behavio-environmental factors. [42-44] Although not every patient with family history of hypertension is at risk of developing hypertension-related MetS but their chances are higher. Screening adult patients with family history of hypertension for MetS needs to be at initial clinical encounter as the development and damage by hypertension-related dysmetabolism start even before the diagnosis is made. Due to this constitutional genetic predisposition and clustering of hypertension-related MetS in families, the family history of hypertension should therefore inform the need to evaluate for hypertension and other components of MetS in order to identify covert and overt cases requiring management. The earlier the primary prevention starts the more likely it is to be beneficial.

This study has shown that MetS was significantly higher in the subjects who were physically inactive. Physical inactivity was reported as an important risk factor for chronic diseases among civil servants in Abakiliki, Southeast Nigeria[45] and in other parts of world such as Ghana[46] and Thai[47]. Although physical inactivity is a global health problem but it occurs disproportionately higher in Nigeria which is a nation in socio-economic and demographic and epidemiological transition. The relevance of physical inactivity as a modifiable risk factor for noncommunicable diseases such as hypertension, obesity, type 2 diabetes mellitus and dyslipidaemia has been reported by previous studies[36,39,40] and identified by World Health Organization. [48] Physical inactivity is associated with each of the principal defining criteria that contributes to MetS.[49-52] The physio-biological mechanism responsible for the beneficial effects of physical activity has been documented to include reduction of blood pressure, increase insulin sensitivity, elevation of HDLcholesterol, reduction of atherogenic cytokine production and improve endothelial function.[6,49] The primary care clinicians should therefore explore the levels of physical activity the patients can accomplish because any physical activity is better than none. This information should not only be limited to the consequences of physical inactivity but also the benefits of physical activity in the overall metabolism and diverse medical conditions.

This study has shown that physical inactivity is the most significant predictor variable of MetS. This finding is consistent with other reports on the relevance of physical inactivity as an important risk factor for metabolic syndrome.[49-52] The finding of this study is very important especially in Nigerian socio-cultural environment where work and leisure-related physical activities and short distance communal trekking is perceived as an indication of suffering and poverty.[39,53] More worrisome in the study area is the role of modernization of means of transportation and communication such as the use of vehicular transport system and mobile cellular communication network.[53] These technologies probably have reduced short and long distance trekking and cycling time which involve energy expenditure. Due to change in family and societal dynamics, there is reduction in domestic, leisure and other societal-related physical activity. Although not every physically inactive patient develops MetS but their chances are higher. The addition of physical inactivity risk factor in patients with MetS needs further attention in primary care clinic in resource-constrained setting. Identifying this problem during clinical encounter therefore avails greater opportunity for health education, health promotion, health maintenance and risk reduction. Patients who have been physically inactive should be encouraged to start physical activity as part of their daily routine.

\subsection{Implications of the Study}

MetS has been the subject of recent research among different populations in Nigeria and adult Nigerian public servants attending NHIS primary care clinic are not spared and this carry great concern for safeguarding the health of the public work force in the study area. As Nigeria develops and adopts western culture, she also accumulates diseases associated with socio-economic and technological development like MetS. MetS can therefore compromise health status of Nigerian public labour force with morbidity and mortality costs. Given the inadequacy of distribution, determinants and deterrents interventions for MetS in the study area, the most effective physician intervention is through primary and secondary prevention. This study therefore has implications for primary care oriented and driven interventions for MetS among the Nigerian public human resources in the study area.

\subsection{Limitations of the Study}

The limitations of this study are recognized by the authors. First and foremost, the sample for the study was drawn from patients accessing care from primary NHIS clinic of the hospital. Hence, the findings of this study may not be general conclusions regarding patients from other NHIS outpatient clinics of the hospital. Thus external generalization of the findings of this study to other primary care NHIS clinic of other tertiary hospitals in Nigeria should be done with caution

In addition, this study was dependent on self-reported 
behavioural factors and family history of component defining criteria for MetS in the first, second and third degree relatives. However, some respondents were either reluctant to give correct information regarding family history of hypertension, diabetes mellitus, abdominal obesity and/or stroke. Some respondents were not sure whether their relatives were afflicted by the cardiometabolic disease or not. This could have led to response acquiescence, social desirable response and recall bias. In order to minimize recall biases the questions were structured in a manner that will enable the researcher obtain information relevant to the objectives of the study. This objectivity was also maintained by not fielding misleading questions. The researchers ensured that questions were not ambiguous or presented to the respondents in such a way as to communicate different meanings that could generate inaccurate and inconsistent responses.

Furthermore, the assessment for the behavioural risk factors of alcohol consumption, tobacco use and diets were not quantitative as regards the metabolic relevance of occasional or rarely use of alcohol or tobacco or consumption of dietary fruits and vegetables which may not predispose to MetS.

\section{Conclusion}

This study has shown that MetS exist among the study population and was significantly associated with old age $\geq 40$ years, female sex, family history of hypertension and physical inactivity. The most significant predictor variable was physical inactivity. NHIS patients in the primary care clinic should be the focus of primary and secondary preventive interventions for MetS.

\section{References}

[1] Alberti KG, Eckel RH, Grundy SM. Harmonizing the metabolic syndrome: a joint interim statement of the International Diabetes Federation Task Force on Epidemiology and Prevention; National Heart, Lung, and Blood Institute; American Heart Association; World Heart Federation; International Atherosclerosis Society; and International Association for the Study of Obesity. Circulation 2009; 120: 1640-45.

[2] Cornier MA, Dabela D, Hernandez TL, Lindstrom RC, Steig AJ, Stob NR, et al. The metabolic syndrome. Endocr Rev 2008; 29: 777-822.

[3] Kelliny C, William J, Riesen W, Paccaud F, Bovet P. Metabolic syndrome according to different definitions in a rapidly developing country of the African region. Cardiovasc Diabetol 2008; 7: 27.

[4] Fezeu L, Balkau B, Kengne AP, Sobngwi E, Mbanya JC. Metabolic syndrome in a sub-Saharan African setting: central obesity may be the key determinant. Atherosclerosis 2007; 193: 70-76.

[5] Eckel RH, Grundy SM, Zimmet PZ. The metabolic syndrome. Lancet 2005; 365: 1415-1428.
[6] Alshehri AM. Metabolic syndrome and cardiovascular risk. J Fam Community Med 2010; 17: 73-78

[7] Isezuo SA, Ezunu E. Demographic and clinical correlates of metabolic syndrome in native African type 2 diabetic patients. J Natl Med Assoc 2005; 97: 557-563.

[8] Isomaa B, Almgren P, Tuomi T, Forsen B, Lahti K, Nissen $\mathrm{M}$, et al. Cardiovascular morbidity and mortality associated with the metabolic syndrome. Diabetes Care 2001; 24: 683689.

[9] Grundy SM, Cleeman JI, Daniels SR, Donato KA, Eckel $\mathrm{RH}$, Franklin BA, et al. Diagnosis and management of the metabolic syndrome: An American Heart Association/ National Heart, Lung and Blood Institute scientific statement. Circulation 2005; 112: 2735-2752.

[10] Grundy SM, Brewer FIB, Cleeman JI, et al. Definition of metabolic syndrome: report of the National Heart, Lung and Blood Institute/American Heart Association conference on scientific issues related to definition. Circulation 2004; 109: 433-438.

[11] Alberti KG, Zimmet P, Shaw J. Metabolic syndrome-a new world-wide definition. A consensus statement from the International Diabetes Federation. Diabet Med 2006; 23: 469-480.

[12] Einhorn D, Reaven GM, Cobin RH, et al. American College of Endocrinology position statement on the insulin resistance syndrome. Endocr Pract 2003; 9:237-252.

[13] Balkau B, Charles MA. Comment on the provisional report from THE WHO CONSULTATION. European Group for the study of Insulin Resistance(EGIR) Diabet Med 1999; 16: 442-443.

[14] Akintunde AA, Ayodele OE, Akinwusi PO, Opadijo GO. Metabolic syndrome: Comparison of occurrence using three definitions in hypertensive patients. Clin Med Res 2011; 9: 26-31.

[15] Ford ES, Giles WH, Dietz WH. Prevalence of the metabolic syndrome among US adults: Findings from the Third National Health and Nutrition Examination Survey. JAMA 2002; 287: 356-359.

[16] Al-Nozha M, Al-Khadra A, Arafah MR, Al-Maatouq MA, Khalil MZ, Khan NB, et al. Metabolic syndrome in Saudi Arabia. Saudi Med J 2005; 26: 1918-1925.

[17] Pemminati S, Prabha Adhikari MR, Pathak R, Pai MR. Prevalence of metabolic syndrome(METS) using IDF 2005 guidelines in a semi urban south Indian(Boloor Diabetes Study) population of Mangalore. J Assoc Physicians India 2010; 58: 674-677.

[18] Gyakobo M, Amoah AGB, Martey-Marbell D, Snow RC. Prevalence of the metabolic syndrome in a rural population in Ghana. BMC Endocr Disord 2012; 12: 25.

[19] Tran A, Gelaye B, Girma B, Lemma S, Berhane Y, Bekele T, et al. Prevalence of metabolic syndrome among working adults in Ethiopia. Int J Hypertens 2011.

[20] Ulasi II, Ijoma CK, Onodugo OD. A community-based study of hypertension and cardio-metabolic syndrome in semi-urban and rural communities in Nigeria. BMC Health Serv Res 2010; 10: 71 
[21] Adediran O, Akintunde AA, Edo AE, Opadijo OG, araoye AM. Impact of urbanization and gender on frequency of metabolic syndrome among native Abuja settlers in Nigeria. J Cardiovasc Dis Res 2012; 3: 191-196.

[22] Ismail MF. Metabolic syndrome among obese Qataris attending primary health care centers in Doha. 2010. J Fam Community Med 2012; 19: 7-11.

[23] Termizy HM, Matauzy M. Metabolic syndrome and its characteristics among obese patients attending an obesity clinic. Singpore Med J 2009; 50: 390-4.

[24] Marchesini G, Melchionda N, Apolone G, Cuzzolaro M, Mannucci E, Grossi E. The metabolic syndrome in treatment seeking obese persons. Metabolism 2004; 53: 435 -40.

[25] 2Surana SP, Shah DB, Gala K, Hoskote SS, Gill N, Joshi $\mathrm{AR}$, et al. Prevalence of metabolic syndrome in an Indian population using the NCEP ATP III. J Assoc Physicians India 2008; 56: 865-8.

[26] Alebiosu Co, Odusan BO. Metabolic Syndrome in subjects with type 2 diabetes mellitus J Natl Med. Assoc. 2004, 96: $817-21$

[27] Puepet FH, Uloko A, Akogu IY, Aniekwensi E. Prevalence of the metabolic syndrome among patients with type 2 diabetes mellitus in urban North-Central Nigeria. Afr $\mathbf{J}$ Endocrinol Metab 2009; 8: 10-12

[28] Meigs JB, Larson MG, D’Agostino RB. Coronary artery calcification in type 2 diabetes and insulin resistance. The Famingham Offspring Study. Diabetes Care 2002; 25: 131319.

[29] Bonora E, Kiechi S, Willet J, Oberholienzer F, Egger G, Bonadonna RC, et al. Carotid atherosclerosis and coronary heart disease in the metabolic syndrome: Prospective data from the Bruneck study. Diabetes Care 2003; 26: 12511257.

[30] Liu S, Manson JE. Dietary carbohydrates, physical inactivity, obesity and the 'metabolic syndrome' as predictors of coronary heart disease. Curr Opin Lipidol 2001; 12: 395-404.

[31] Park HS, Oh SW, Cho WH, Kim YS. The metabolic syndrome and associated lifestyle factor among South Korean adults. Int J Epidemiol 2004; 33: 328-336.

[32] Lemieux I, Pascot A, Couillard C, Lamarche B, Tchernof A, Almeras N, et al. Hypertriglyceridemic waist: a marker of the atherogenic metabolic triad(hyperinsulinemia, hyperapolipoprotein $\mathrm{B}$, small dense LDL) in men. Circulation 2000; 102: 179-184.

[33] Okeahialam BN, Ogbonna C, Otokwula AE, Joseph DE, Chuwak EK, Isiguzoro IO. Cardiovascular Epidemiological Transition in a Rural Habitat of Nigeria: The Case of Mangu Local Government Area. West Afr J Med 2012; 31: 14-18.

[34] Araoye MO. Sample size determination. Research Methodology with Statistics for Health and Social Sciences, Ilorin, Nathadex Publishers, 2004; p.115-121.

[35] Iloh GUP, Ikwudinma AO Abdominal obesity in adult Nigerian Africans: prevalence and co- occurrence with cardio-metabolic risk factors in a resource poor setting of a rural hospital in Eastern Nigeria. American Journal of Health Research 2013; 1: 73-80.
[36] Iloh GUP, Amadi AN, Ikwudinma AO, Njoku PU. Prevalence and Family Biosocial Predictors of Abdominal Obesity among Adult Nigerian Africans in a Resource Constrained Setting of a Rural Hospital in Eastern Nigeria. European Journal of Preventive Medicine. 2013; 1:70-78.

[37] Iloh GP, Ikwudinma AO, Obiegbu NP. Obesity and its cardio-metabolic co-morbidities among adult Nigerians in a primary care clinic of a tertiary hospital in South-Eastern Nigeria. J Fam Med Primary Care 2013; 2: 20-26

[38] WHO. Survey of the STEPwise approach for the survellaince of risk factors for non-communicable diseases, Brazzaville, WHO, Region office for Africa, 2007.

[39] Iloh GUP, Chuku A, Obiegbu NP, Ofoedu JN, Ikwudinma AO. Frequency of cardiovascular risk factors in adult Nigerians with family history of non-communicable cardiovascular disease in a primary care clinic of a tertiary hospital in a resource-constrained environment of Eastern Nigeria. American Journal of Health Research 2013; 1(1): 17-25.

[40] Oladapo OO, Salako L, Sodiq O, Shoyinka K, Adedapo K, Falase AO. Prevalence of cardiometabolic risk factors among a rural Yoruba South Western Nigerian population. A population-based survey. Cardiovasc J Afr 2010; 21: 26-31.

[41] Gundogan K, Bayram F, Capak M, Tanriverdi F, Karaman A, Ozturk A. et al. Prevalence of metabolic syndrome in the Mediterranean region of Turkey: evaluation of hypertension, diabetes mellitus, obesity and dyslipidaemia. Metab Syndr Relat Disord 2009; 7: 427-34.

[42] Caulfield M, Munroe P, Pembroke J, Samani N, Dominiczak A, Brown M, et al. Genome-wide mapping of human loci for essential hypertension. Lancet 2003; 361: 2118-2123.

[43] Goldstein IB, Shapiro D, Guthrie D. Ambulatory blood pressure and family history of hypertension in healthy men and women. Am J Hypertens 2006; 19: 486-491.

[44] Yoon PW, Scheuner MT, Khoury MJ. Research priorities for evaluating family history in the prevention of common chronic diseases. Am J Prev Med 2003; 24:128-135.

[45] Ugwuja EI, Ogbonna NC, Nwibo AN, Onimawo IA. Overweight and obesity, lipid profile and atherogenic indices among civil servants in Abakiliki, South Eastern Nigeria. Ann Med Health Sci Res 2013; 3: 13-18.

[46] Mogrel V, Mwinlenaa PP, Oladele J, Amalba A. Impact of physical activity levels and diet on central obesity among civil servants in Tamale metropolis. J Med Biomed Sci 2012; $1: 1-9$.

[47] Dancy C, Lohsoonthorn V, Williams MA. Risk of dyslipidaemia in relation to level of physical activity among Thai professionals and office workers. Southeast Asian J Trop Med Public Health 2008; 39: 932-941.

[48] WHO. Global strategy on diet, physical activity and health. Bulletins of the WHO 2006; 5: 16-18.

[49] Lee IM. Effect of physical inactivity on major noncommunicable diseases worldwide: an analysis of burden of disease and life expectancy. Lancet 2012; 380: 219-29.

[50] Katzmarzyk PE, Church TS, Blair SN. Cardio-respiratory fitness attenuates the effects of the metabolic syndrome on all cause and cardiovascular disease mortality in men. Arch Intern Med 2004; 164: 1092-7. 
[51] Lakshminarayanan S, Bala SM, Ramanujam M, Kannan G. Effectiveness of physical activity promotion in blood pressure and blood sugar reduction: A community-based intervention study in rural south India. J Fam Community Med 2012; 19: 81-87.

[52] Sobngwi E, Mbanya JC, Unwin NC. Physical activity and its relationship with obesity, hypertension and diabetes in urban and rural Cameroon. Int J Obes.Relat Metab Disord 2003; 26: 1009-16.
[53] Iloh GUP, Obiegbu NP, Abali Chuku, Ikwudinma AO. Predictors of limitations of physical activities of daily living among geriatric Nigerians with musculoskeletal disorders in under-resourced environment of a primary care clinic of a tertiary hospital in Eastern Nigeria. European Journal of Preventive Medicine 2013; 1: 37-45 